\title{
De mitos y sublimes digitales: movimientos sociales y tecnologías de la comunicación desde una perspectiva histórica
}

Emiliano Treré, Alejandro Barranouero

\begin{abstract}
This paper aims at interpreting the relationship between social movements and communication technologies, from the perspective of a set of critical frameworks which, in recent years, have warned of the processes of sublimation and creation of myths linked to the birth of each "new" technology. Within this context, civic movements are observed both as spaces of reproduction of enthusiastic discourses on ICTS, at the service of diverse power spheres -corporations, governments, media, etc.-, as well as of experimentation and technological appropriation, in which, through daily practices, a more complex and demystified perspective of communication technologies is produced. We propose a chronological analysis across three case studies, based in different contexts, which aim at illustrating the premature approximations to the role of communication technologies in social uprisings: the Zapatista informational guerrilla, the 'smart mobs' in the Philippines, the 'Anomalous Wave' and the '5 Stars Movement' in the Italian context. We conclude underlining the need to move towards the collective construction of knowledge through synergies between academia and social movements as a way to question techno-euphoria as well as to avoid the mistakes of the past.
\end{abstract}

KeYwords: Social movements, cyberactivism, communication technologies, Web 2.0, digital myths, techno-myths

En este vacio entra el relato de Tecnópolis, con su énfasis en el progreso sin límites, en derechos sin responsabilidades y en tecnología sin costos

Neil Postman, 1994: 231 


\section{El embrujo de las tecnologías}

Los mitos asociados al nacimiento de cada "nueva" tecnología de la información han sido una constante histórica desde la invención de la imprenta en el siglo XV (Rhodes y Sawday, 2000), hasta la aparición de otras innovaciones fruto del pensamiento moderno y la Revolución industrial (s. XVIII y XIX), como el telégrafo óptico, la fotografía o la telefonía en el siglo XIX, y el cine, la radio y la televisión en el XX. En los dos últimos siglos, las referencias a un cambio de era, ciclo o tiempo histórico se han hecho cada vez más frecuentes, como si las tecnologías en sí mismas fuesen el principal detonante de las transformaciones históricas. Esta tendencia al tecno-determinismo, lejos de desaparecer, se ha profundizado aún más si cabe en un panorama acelerado de mutaciones tecnológicas, en el que Internet y la telefonía móvil parecen actuar, para muchos, a modo de las caprichosas manillas que agitan el reloj de la historia.

Empero, la distancia histórica evidencia que la aparición de cada tecnología informacional ha venido acompañada de relatos mitológicos, que son en realidad fruto en realidad de un pensamiento moderno que creyó haber superado las barreras del espíritu y la naturaleza con su confianza ciega en la razón y la técnica. A diferencia de los relatos de corte racional, James Carey (1992: 18) advirtió hace unos años del predominio de un modelo "ritual" o "histórico-religioso" en la comprensión popular o científica de las tecnologías de la información, puesto que, históricamente, los discursos acerca de la comunicación han tendido a sobredimensionar el poder de la técnica, hasta atribuirle cualidades quasi-mágicas.

En el terreno académico, la reflexión acerca de los medios ha supuesto una fuente inagotable de discursos tecno-deterministas. Esto es fácil de comprobar en los propios orígenes de la disciplina en EE.UU., durante el período de entreguerras, en una Mass Communication Research que contribuyó a divulgar una visión mecanicista, lineal y tecno-optimista acerca de los efectos de las tecnologías sobre la sociedad, en buena medida portadora de los intereses comerciales y geoestratégicos de las empresas y estados que sustentaron las primeras investigaciones (Saperas, 1992). Dentro de esta corriente, la propia teoría modernizadora y difusionista de los medios, importada desde EE.UU. a buena parte del Sur del planeta, sostuvo el mito de los medios eran "multiplicadores mágicos" del desarrollo, puesto que permitian modificar las conductas de los pueblos "atrasados" del Sur en torno a los valores "modernos" y capitalistas del Norte (Lerner, 1958).

Los ecos de estas primeras aproximaciones han vuelto a resonar con fuerza a finales del siglo pasado en torno a Internet y otras tecnologías comunicacionales. De hecho, discursos como el de la "sociedad de la información" no han sido más que una revitalización del mito difusionista que evalúa el grado de desarrollo de un país en función de su número de medios (Schramm, 1964); o, en otras palabras, la confusión de cantidad con la calidad de la información, que participa de la "mística del número" entronizada por la Ilustración, y que ha venido denunciando Armand Mattelart en distintos volúmenes que 
dan cuenta de una ambiciosa genealogía tecno-desmitificadora (Mattelart, 2002: 15)'.

Con el nuevo ciclo de movilizaciones que arranca en 2011 -Primavera Árabe, 15M, Occupy, etc., o en 2013 las protestas en Turquía, Brasil o Egipto-, el universo mitológico se ha reciclado nuevamente en torno a una Web 2.0 (0'Reilly, 2005) que suele percibirse como un idílico espacio de participación y libertad (Allen, 2008; Fuchs, 2012; Grönlund, 2009; Scholz, 2008), en el que se reconstruyen los lazos sociales, y en el que incluso se gestan revueltas.com, revoluciones Facebook o Twitterrevoluciones². Una vez más, los discursos en torno a la metáfora comodín de la red (2012: 125) y a las posibilidades emancipadoras de las redes sociales, se han convertido en una réplica casi exacta de los relatos fabulosos que acompañaron, por ejemplo, a la invención del telégrafo en el último cuarto del siglo XIX. A este respecto, bastaría con sustituir en el siguiente pasaje "telégrafo" por Internet, ciberespacio o redes sociales, tal y como nos alienta a hacer Carey para alertarnos del inocente triunfalismo con el que nos enfrentamos a cada "nueva" tecnología (Marvin, 1988) ${ }^{3}$ “iCuán potente es, por tanto, el telégrafo destinado a convertirse en el motor civilizatorio del mundo! Une a través de un cordón vital a todas las naciones de la Tierra. Es imposible que sigan existiendo los viejos prejuicios y confrontaciones, en tanto tal instrumento innovador permita el intercambio de ideas entre todas las naciones de la Tierra" (Carey, 1992: 208-209).

Desde una perspectiva histórica, el presente artículo tiene como objetivo reflexionar acerca de la relación entre movimientos sociales y TICs, en tanto que estos colectivos son espacios de reproducción de discursos tecno-entusiastas que emanan de distintas esferas de poder-corporaciones, administraciones públicas, medios, etc.-. Pero, a la vez, estos movimientos son escenarios privilegiados de experimentación e innovación tecnológica, en los que, a partir de la práctica cotidiana, se preconiza una visión más compleja y desmitificada de las tecnologías informacionales.

\section{UN BREVE RECUENTO HISTÓRICO DE LA CRITICA A LA TÉCNICA}

Si bien no muy conocidos por parte de activistas o académicos, son numerosos los trabajos que a lo largo de la historia del pensamiento han intentado dar cuenta de los procesos de sublimación y mitificación asociados a la técnica y, en particular, a las tecnologías de la información. De hecho, cabe rastrear sus orígenes más remotos en la larga tradición

\footnotetext{
1 Lo mismo es aplicable a otros relatos mitológicos de la década de 1990 como el de las "autopistas de la información" o de la muy sugerente "sociedad del conocimiento", que, en su uso cotidiano, fue desprendiéndose del contenido critico de ciertas aproximaciones pioneras.

2 Buen ejemplo de esto, lo constituyen llamativos titulares durante el 2011 como el del reportaje "Twitterrevolución", de El País Semanal (13/3/11), acerca del papel de esta red social en las Primaveras Árabes

3 De ahi la sugerente critica de Marvin (1988) cuando titula su texto "Cuando las antiguas tecnologias eran nuevas" (When old technologies were new), centrado en los relatos mitológicos a propósito del nacimiento del teléfono y electricidad en el siglo XIX. Sobre el tópico de la "novedad", consultar también Gitelman (2006).
} 
de la filosofía de la técnica, o en los hoy denominados estudios de ciencia, tecnología y sociedad. A este respecto, Carl Mitcham (1989) planteó hace unos años una interesante genealogía en torno a las dos grandes aproximaciones teóricas a la técnica que han coexistido desde los orígenes de la Modernidad. La primera tradición, de carácter "ingenieril" y eminentemente "explicativa", ya presente en el siglo XVII en obras precursoras como las de Ernst Kapp o Frederich Dessauer, no se caracterizó por su cuestionamiento de la tecnología, sino por poner el acento en su estructura interna y su naturaleza independiente con respecto al ser humano. En este entorno se situarian, grosso modo, las teorías difusionistas o las de los "medios como extensiones" del ser humano, en la línea de Marshall McLuhan y sus continuadores.

En segundo lugar, desde principios del siglo XX, Mitcham señala la aparición de una filosofía de carácter "humanista", que incide en la relación dialéctica entre tecnología y sociedad, y que intenta ofrecer una comprensión hermenéutica y antropológica de la técnica como un elemento más de la cultura. Junto a precursores como Ortega y Gasset (1997), esta tradición tuvo un impulso significativo en Alemania, en buena medida marcada por las tragedias asociadas al uso tecnológico durante las dos guerras mundiales. De ahí proceden, por ejemplo, las reflexiones en clave existencialista y ontológica de Martin Heidegger $(1984,1989)$ y la extensa crítica de la Escuela de Frankfurt, que advirtió acerca de las amenazas de la reproducción tecnológica sobre la cultura (Adorno y Horkheimer, 1994), o de la racionalidad técnica como ideología legitimadora de un orden social particular (Marcuse, 1999; Habermas, 1997). En la tradición "humanista" cabría destacar asimismo a dos precursores hoy un tanto olvidados en el campo de la comunicación. El estadounidense Lewis Mumford planteó a principios de siglo XX una historia de la tecnología en tres oleadas, en la que incide en la "deuda" que esta "tiene contraida con las mitologías" (1971: 200), y unas mitologías entre las que se podria situar la idea de progreso en base a la explotación técnica e intensiva de la naturaleza (Mumford, 2010, 2011). Por su parte, el francés Jacques Ellul puso el foco en el carácter de autocrecimiento de la tecnología, hasta casi autonomizarse del ser humano, y llegar a sustituir valores éticos por mitos como los de la eficiencia, la utilidad y la maximización: "Todos los hombres de nuestro tiempo están de tal manera apasionados por la técnica, de tal modo seguros de su superioridad [...] que todos ellos, sin excepción, están orientados hacia el progreso técnico, que en él trabajan todos, que en cualquier oficio todos buscan perfeccionamientos técnicos" (Ellul, 1960: 85).

En la actualidad, estaríamos asistiendo a la que es, tal vez, una nueva etapa en la reflexión tecnológica en la que destacan preocupaciones éticas propias de la segunda mitad del siglo XX como la cuestión ambiental o el impacto de las nuevas tecnologías informacionales en las sociedades postindustriales. Junto a las reflexiones en clave ecológica acerca de la necesidad de responsabilidad (Jonas, 1985) o autocontención (Illich, 1985) del ser humano en su uso de la tecnología, en el campo estricto de los medios de comunicación y las TIC cabe destacar el papel desmitificador que en los últimos años viene jugando la economía política de la comunicación (Dyer-Witheford, 1999; Flichy, 
2003; Fuchs, 2008; Mattelart, 1995, 1999, 2002; McChesney, 2013; Mosco, 2011), que alerta acerca de los condicionantes políticos y económicos que atañen a la producción, distribución o consumo tecnológicos, o, en la acertada expresión de Langdom Winner (2008), del hecho de que los artefactos tecnológicos tienen "cualidades políticas", puesto que encarnan ciertas formas de poder y autoridad específicas. En su mirada diacrónica, la economía política suele actuar en convergencia con la historia de la comunicación (Darnton, 2011; Gitelman, 2006; Marvin, 1988; Nye, 1994), que ubica la aparición de los diferentes media -y hoy Internet y sus metamorfosis- en un continuum histórico de relatos tecno-ilusionantes. Asimismo, asistimos en los dos últimos años a un repunte de las críticas al tecnodeterminismo en una generación renovada de autores (Carr, 2011; Morozov, 2012, 2013; Powers, 2010; Thierer, 2010; Turkle, 2011) ${ }^{4}$ que advierten de ciertos riesgos de Internet y de redes sociales corporativas como Facebook, entre otros: la vigilancia y el control, la explotación del trabajo inmaterial, o el comercio con la privacidad, etc.

\section{De mitos, Sublimes e imaginarios tecnológicos}

Desde nociones como las de "tecno-mito", "sublime digital" o "tecno-imaginario", un conjunto de constructos críticos nos ayudan hoy a reflexionar acerca de nuestra relación con las tecnologías y, en particular, sobre su empleo y apropiación por parte por la sociedad civil organizada.

En primer lugar, conviene destacar la línea de trabajos abierta a partir de la revitalización del concepto de "mito" para el análisis cultural por parte del semiólogo Roland Barthes. Ya en la década de 1970, el francés advertía de la existencia de narraciones mitológicas asociadas a los distintos artefactos culturales o tecnológicos de su época, como por ejemplo a las imágenes del cine o la publicidad. Desde una perspectiva emparentada con la de noción de "ideología", los mitos son para Barthes distorsiones de la realidad, que alejan a los seres humanos de una comprensión más compleja de la misma y que trabajan, en último término, al servicio de los intereses de unas clases y poderes dominantes. Los mitos no niegan la realidad, sino que la revelan de manera seductora, eliminando su política y su historia, e invocando para ella un final deseado e inevitable. Aplicados a las tecnologías, los mitos "las purifican o las hacen inocentes, les dan una justificación natural y eterna, les proporcionan una claridad que no es la de una explicación sino la de la aseveración de un hecho" (Barthes, 1972: 143). Desde esta perspectiva, Almirón y Jarque (2008: 20) planteaban hace unos años que el discurso digital es mítico en el sentido de que "se establece a sí mismo como fedatario de una realidad -la revolución tecnológico-

4 De ahi la sugerente critica de Marvin (1988) cuando titula su texto "Cuando las antiguas tecnologias eran nuevas" (When old technologies were new), centrado en los relatos mitológicos a propósito del nacimiento del teléfono y electricidad en el siglo XIX. Sobre el tópico de la "novedad", consultar también Gitelman (2006). 
digital- que se confunde con el mito -el nacimiento de una nueva era- y que niega la historia, no es racional y, al contrario de lo que anuncia, es ideológicamente conservador".

En segundo lugar, interesa emparentar la noción de "mito" con la de "sublime tecnológico", glosada por el historiador David Nye $(1994)^{5}$ y recuperada en tiempos recientes por Vincent Mosco en sus reflexiones acerca del "sublime digital" (2011). Para el investigador canadiense, el concepto insiste en la mirada de trascendencia, asombro o sobrecogimiento con la que el individuo moderno se acerca a cualquier artefacto fruto de su ingenio, y que acaba por sustituir la sublimación asociada a las maravillas naturales que existió en la época pre-moderna. Al igual que en los mitos barthesianos, las tecnologías tienden a percibirse, al menos en su origen, a través "historias seductoras que encierran promesas incumplidas o que no pueden cumplirse" (Mosco, 2011: 49). De hecho, las narraciones fabulosas asociadas a Internet son comparables al universo de promesas que acompañó en su día al telégrafo, el teléfono, la radio o la televisión por cable (ibíd., 209-250) y, que, en muchos casos, preconizó un "ocaso" o a una "transformación señera que haría época en la historia humana y que trascendería el tiempo (el fin de la historia), el espacio (el fin de los límites geográficos) y el poder (el fin de la política)" (ibíd., 16). Una vez más, los sublimes digitales tienden a olvidar que cualquier tecnología está constituida por "una cultura que crea significados y por una economía política que lo dota de poder" (ibíd., 211).

En tercer lugar, tecno-mitos y sublimes se completan con la interesante revitalización que Daniel H. Cabrera $(2004,2006)$ emprende de la noción de "imaginario" de Cornelius Castoriadis aplicada a las $\mathrm{TIC}^{6}$. Con el objeto de evitar la adscripción tradicional del concepto a falseamiento o distorsión, el investigador lo interpreta en tanto que imaginación, imagen, afectos o deseos con los que el ser humano se piensa a sí mismo y dota de sentido el mundo. Estas representaciones son más que pura ideología o utopía, puesto que llegan a trascenderlo y a determinar lo que es imaginable, pensable y deseable para el individuo y la sociedad. Según Cabrera, el imaginario asociado a las TIC es hoy el imaginario social "instituido e instituyente" de la sociedad contemporánea, puesto que, al tiempo que alienta esperanzas de cambio a los actores sociales a partir de sus empleos tecnológicos (ej. las visiones libertarias y hacktivistas de Internet en confrontación con las militares que se dieron con el nacimiento de Internet), se acompaña de falsos discursos-promesas acerca de una nueva época, caracterizada, coincidiendo con Mosco, por el "fin de las ideologías" y por una idea de progreso basada, en exclusiva, en la "inevitable" innovación tecnológica. Este "solucionismo" de las TIC, a decir del último trabajo de Morozov (2013), ya había sido denunciado en los preludios de Internet por autores que, sin embargo, fueron un tanto incomprendidos en su época como Neil Postman (1994) o Theodor Roszak (1994).

5 Además de la obra clásica de Edmund Burke sobre el concepto de "sublime" en torno a lo natural, las primeras reflexiones acerca del sublime tecnológico se deben a Leo Marx y Perry Miller.

6 Diferente, en este sentido, del texto de Flichy (2003) sobre imaginarios tecnológicos. 


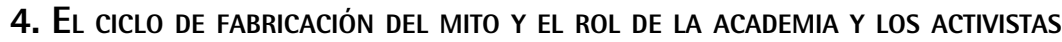

Pero si mitos, sublimes o imaginarios suelen desplazar el componente político, histórico o material del mundo, un estudio profundo de los orígenes de los mismos pueden contribuir a restaurarlo o regenerarlo. Conviene partir para ello, como es natural, situando el origen último de los tecno-mitos en los discursos apologéticos que acompañan al lanzamiento

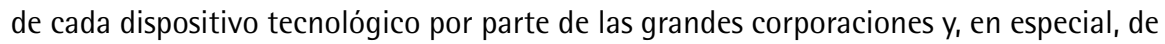
las propias empresas productoras de telecomunicaciones, informática y software o acceso al ciberespacio, por lo que algunos autores los han definido como "mercado-utopías" (Bustamante, 2009) o "determinismo tecnomercantil" (Mattelart, 2002). Estos intereses comerciales suelen permear con rapidez la agenda de gobiernos nacionales y de las grandes instituciones transnacionales implicadas en la transferencia tecnológica (Pinto, 2013), puesto que buena parte de su legitimidad de la politica contemporánea se basa hoy "en la identificación con estas visiones sobre el futuro" (Mosco, 2011: 85). En último término, la construcción y reproducción de los elementos mágicos del ciberespacio queda apuntalada a partir de "su difusión acrítica e hiperbólica por parte de los medios de comunicación" (Almirón y Jarque, 2008: 56), una de las principales instancias socializadoras y creadoras de poderosos imaginarios populares que incitan al hiper-consumo tecnológico y sus fatales consecuencias sociales y ecológicas (Maxwell y Miller, 2012).

Pero el tecno-determinismo también impacta en la propia relación que los movimientos sociales mantienen con las TIC. En este sentido, y de acuerdo a Sádaba, es posible apreciar una evolución desde las percepciones primeras, de tipo "reactivo, defensivo o pasivo", hasta una actividad "más propositiva" con respecto a ellas, que en tiempos recientes ha derivado en una hegemonía de las visiones tecno-utópicas (Sábada, 2012: 782). La evolución en los movimientos sociales también se percibe en la propia investigación sobre Internet, en la que Wellman $(2004,2011)$ identifica tres etapas: una primera (199598), en la que se alternan discursos utópicos y distópicos; una segunda (1998-2003), en la que la investigación empírica y el uso cotidiano contribuyen a un cierto alejamiento de los miedos distópicos y las esperanzas utópicas; y una tercera (2004-hoy), en la que se avanza hacia una comprensión más compleja, que entiende que lo online y lo offline, lejos de ser compartimentos estancos, son territorios híbridos e interrelacionados. No obstante, las irrupciones sociales de 2011 han revitalizado los discursos entusiastas, esta vez en torno a la Web 2.0 y las redes sociales -en especial Facebook y Twitter-, en las que ciertos sectores de la academia, los medios o el activismo sitúan los fundamentos de una auténtica revolución de tipo político y comunicacional, asociada a un componente participativo y dialógico, que en el caso de estas plataformas online parece ser mayor que en las precedentes. De hecho, en los últimos tiempos han sido frecuentes los diálogos e interferencias entre movimientos sociales y academia, desde el momento en que, en espacios como la Puerta del Sol en Madrid, la Plaza de Syntagma en Atenas o el Zucotti Park en Nueva York, los activistas se han hecho eco de nociones que proceden, en buena 
medida, del discurso académico, y que subrayan el poderoso poder político de las redes sociales (Shirky, 2011), como las de "auto-comunicación de masas" (Castells, 2009, 2013); "inteligencia colectiva" (Lévy, 2004) o "multitudes inteligentes" (Rheingold, 2004).

Es decir, en vez de una evolución lineal desde lo sublime hasta una visión más compleja, estaríamos hablando de ciclos de tecno-mitificación y tecno-desmitificación con la aparición de cada nueva tecnología. Y en esta línea, aunque se reconocen mitos en forma de descaradas declaraciones de amor con respecto a su supuesto poder liberador, en la mayor parte de las ocasiones la fascinación académica y activista no resulta tan evidente y se muestra de forma sutil, latente y engañosa.

Por otra parte, el final de lo sublime se sitúa en el momento en que las tecnologías ingresan al ámbito de lo común y lo corriente y dejan de inspirar grandes sueños visionarios para la transformación social. En otras palabras, es necesario que la tecnología se "banalice" con el uso, entendiendo lo "banal", no como trivialidad sino como ordinariedad de empleos y apropiaciones (Atton, 2002; Schwarzenegger, 2012): "El auténtico poder de las redes no aparece durante su período mítico, cuando son bien recibidas por su habilidad para traer consigo la paz mundial, renovar a las comunidades, o poner fin a la escasez, la historia, la geografía o la política; sino que su impacto social crece cuando las tecnologías se vuelven banales, o literalmente (como en el caso de la electricidad) o en sentido figurado, se les condena al olvido" (Mosco, 2011: 43). En el caso concreto de los movimientos sociales, tras la euforia tecnológica de los primeros momentos, la desmitificación sería una consecuencia directa del uso cotidiano de las TIC en el denominado "periodo de latencia" (Melucci, 2011), en el que disminuye la visibilidad de los movimientos, pero no su actividad.

En las siguientes secciones, se muestra cómo esta dialéctica entre la tecno-mitificación y desmitificación en relación con el ciberactivismo ha sido una constante histórica tanto en movimientos como en academia, en especial desde la expansión de Internet y en el propio tránsito desde la Web 1.0 a la Web 2.0. Estos estudios de caso ilustran entonces las dos tendencias opuestas identificadas: Ios análisis precipitados, sesgados y entusiastas acerca de las TIC, y las aproximaciones más integrales que insertan el rol de la tecnología en un conjunto más complejo de "mediaciones" (Martín Barbero, 1987) y "prácticas relacionadas con los medios" (Couldry, 2004).

\section{LoS TECNOMITOS ZapatistaS, MÁs ALLÁ dE LA GUERRA CIBERNÉTICA}

El movimiento zapatista surgió en 1994 como una rebelión local de un grupo de campesinos y pueblos indígenas en las tierras altas de Chiapas (México), pero pronto adquirió dimensiones globales gracias a la creación de una sólida red internacional de alianzas y estrategias internacionales en contra de la globalización neoliberal. Internet jugó un papel importante en el levantamiento, y sobre todo en la difusión mundial de la protesta y en 
la construcción de redes de apoyo, hasta el punto de que Manuel Castells (1998) Ilegó a definir al Ejército Zapatista de Liberación Nacional (EZLN) como "el primer movimiento de guerrilla informacional". Por su parte, Harry Cleaver (1994) ha argumentado que el trabajo político del movimiento zapatista representa un tipo de activismo que utiliza el ciberespacio como "entramado electrónico de la lucha" (electronic fabric of struggle). En su opinión, las redes zapatistas se organizaron bajo el principio, expresado por el propio EZLN, de articular la lucha con otros movimientos de protesta a nivel mundial, mediante la articulación de redes de solidaridad. Así, el movimiento se ha caracterizado porque sus activistas no actuaron de forma individual, sino que se apropiaron de las tecnologías para interactuar y colaborar de muchas maneras, en especial con el entorno local más próximo local y de carácter offline. Cleaver apunta asimismo que las tecnologías en línea permitieron una comunicación más eficaz entre individuos y grupos, facilitaron el acceso a una información antes más dispersa y fragmentada, y redujeron cierto poder de ocultamiento ejercido por los medios de comunicación tradicionales.

De estos análisis deriva que la insurrección zapatista sea considerada hoy prototipo o ejemplo paradigmático de "guerrilla informativa" y para algunos incluso sinónimo de "guerra en red" y "cyberactivismo". Sin embargo, si profundizamos en el rol de la mediación tecnológica dentro de la insurrección, ha habido también voces críticas contra estas interpretaciones primeras. Este es el caso de Thea Pitman (2007), quien denunció la mitificación implícita, y a veces intencional, en los primeros análisis, y enfatizó una serie de factores desatendidos a causa de la precipitación. En primer lugar, Pitman (2007: 87) subraya la confusión terminológica que se ha desarrollado alrededor de la insurrección zapatista y el papel de las tecnologias online. En particular, un grave error por parte de la mayoría de los comentaristas fue considerar sinónimos dos términos acuñados por los analistas militares David Ronfeldt y John Arquilla: cyberwar y social netwar. El primer término fue acuñado por los dos autores en 1993, antes de la emergencia del EZLN, mientras que el segundo fue usado a partir del 1996, casi exclusivamente en relación con las acciones de los zapatistas (Ronfeldt et al. 1998). Con la expresión cyberwar los dos autores estadounidenses se referian a guerras informáticas llevadas a cabo a través de Internet, en particular a través de prácticas de hacking como en el caso de la guerra de Kosovo de 1999. Con el segundo concepto, los estudiosos, en cambio, ampliaban la mirada considerando la social netwar, no como una simple función de la Red (Ronfeldt et al. 1998: 11), sino una nueva forma de protesta desarrollada por diferentes grupos horizontales que adoptan múltiples formas de resistencia, entre las cuales Internet juega un importante papel, a nivel organizacional y comunicativo. Así, si el énfasis del primer término se situaba en las estrategias informacionales online, el segundo pretendia captar las complejas relaciones entre viejas y nuevas tecnologias, y analizar, por un lado, los repertorios tradicionales de las protestas y, por otro, los más innovadores a partir del uso de Internet y otras TIC. Pitman destaca hábilmente cómo la opinión popular llegó a confundir la terminología original de Ronfeldt y Arquilla combinando los términos 
cyberwar y social netwar para que ambos llegaran a significar exclusivamente "guerra llevada a cabo en Internet".

Diversos informes periodísticos de tipo sensacionalista han contribuido a amplificar esta tendencia, en connivencia con declaraciones entusiastas de funcionarios del Gobierno de México y otros análisis derivados del mundo académico. La figura del Subcomandante Marcos, cuya mitología ha sido analizada, entre otros, por Russell (2005), también contribuyó a inflamar el arrebato tecnológico. Pero las explicaciones más detalladas acerca del levantamiento manifiestan una serie de factores minusvalorados entre los estudiosos, entre los que cabria destacar el hecho de que las marchas y las reuniones offline tuvieron una importancia crucial, y en especial en el plano simbólico, a la hora de extender la idea de que los zapatistas eran dignos representantes de la lucha mundial contra el neoliberalismo globalizado. En segundo lugar, otros medios tradicionales jugaron un papel central para el éxito de las movilizaciones zapatistas. Es el caso, por ejemplo, del periódico $L a$ Jornada que se transformó en el órgano de difusión oficial de los mensajes del Subcomandante (Hellman, 2000); o de las propias radios locales que contribuyeron a difundir sus discursos, reforzar lazos locales y coordinar las protestas (Bob, 2005). Finalmente, cabe destacar que los análisis académicos Ilegaron a transmitir una idea sobredimensionada de la relativa "novedad" de las apropiaciones tecnológicas, cuando el éxito en su mayoría no tuvo tanto que ver con tácticas innovadoras de lucha en línea, sino con una difusión más tradicional de información a través de los medios convencionales fuera del ámbito digital (prensa, radio y televisión).

\section{FILIPINAS Y LA FÁBULA DE LAS MULTITUDES INTELIGENTES}

Otro ejemplo útil para evidenciar la construcción de tecno-mitos por parte de la academia, con réplicas en el activismo, es el caso de las movilizaciones en Filipinas de 2001, en las que se relata que una convocatoria a través de teléfonos móviles fue capaz de convocar a miles de personas en las calles de Manila en un proceso que llevó derrocamiento del presidente Estrada. Nuevamente, los primeros análisis subrayaron el papel revolucionario jugado por la tecnología, en este caso telefonía móvil, dentro de este proceso. Este es el caso del conocido texto de Howard Rheingold (2004), que encontró en Filipinas su inspiración para acuñar el concepto de "multitudes inteligentes" (smart mobs) a fin de describir el proceso a través del cual los sectores populares habían logrado conectarse por celular hasta el triunfo, en una protesta "espontánea" que no contó con organización previa como la de los movimientos de corte más tradicional.

Recuentos posteriores han matizado este tipo de aproximaciones acerca del revolucionario papel movilizador de las telecomunicaciones. En particular, Rheingold ha sido criticado por el tecno-centrismo de su visión, que ignora importantes aspectos contex- 
tuales donde estas tecnologías están insertadas (Kotamraju, 2005). Un excelente esfuerzo por contextualizar el papel de la tecnología en la insurrección filipina es proporcionado por Rafael (2003) que, aún sin criticar directamente a Rheingold, analiza las limitaciones impuestas por las dinámicas de clase dentro del acontecimiento, y, en particular, el importante fetichismo tecnológico de la clase media filipina (Rafael, 2003: 412), que, según el autor, estaba más preocupada por conseguir reconocimiento por parte de las autoridades que en derrocar las estructuras autoritarias. Pero la crítica más contundente al determinismo tecnológico de las multitudes inteligentes vino desde el teórico de los movimientos sociales Charles Tilly (2005), quien, a partir de una perspectiva socio-histórica, contribuyo a redimensionar la verdadera función de la telefonía en las luchas. En primer lugar, el sociólogo estadounidense destaca, y desde una perspectiva socio-histórica más amplia, cómo a comienzos del siglo XXI Filipinas se había integrado ya en los circuitos internacionales de la comunicación, con lo que los gobernantes filipinos carecian de los mecanismos de censura propios de países como Birmania y Bielorrusia. Por otra parte, Tilly subrayó cómo el uso de mensajes de texto a través de teléfonos móviles fue importante pero no tan decisivo durante la campaña contra Estrada. Si bien estas formas de comunicación de bajo coste permitieron a las "multitudes" una mayor rapidez a la hora de conectarse, los repertorios de acción siguieron pareciéndose sobremanera a los de movimientos estatales anteriores, e incluso a los de movilizaciones en otras partes del mundo, esto es: Ilamamientos a organizaciones previamente establecidas, asambleas, desafíos a la autoridad, manifestaciones, marchas, etc.

En segundo lugar, lo que Tilly demuestra es la "banalidad" de muchas de estas prácticas, al insertarlas en continuidades socio-históricas de más largo alcance y criticar el supuesto papel revolucionario que algunos autores habían atribuido a la mediación de los móviles. Desde su óptica, la única manera de evitar la trampa del tecno-determinismo consiste en tener en cuenta la complejidad de los contextos políticos y sociales en los que surgen y se desarrollan las prácticas, desde la premisa de que las mediaciones tecnológicas han acompañado siempre el quehacer de los movimientos y no representan una novedad revolucionaria que pueda alterar por sí sola otras dinámicas mucho más complejas y que vienen formándose e instaurándose desde hace siglos.

\section{Tecno-mitos en el contexto italiano: Onda Anómala y $\mathbf{5}$ Stelle}

El escenario italiano también ofrece algunos casos interesantes para la exploración de la historia reciente de la mitificación de las tecnologías por parte de academia y movimientos sociales. En este contexto interesa destacar, en primer lugar, el ejemplo del movimiento estudiantil Ola Anómala o Gigante (Onda Anomala), que en 2008 devino la revuelta estudiantil italiana más importante desde Mayo del 1968 y el Movimiento de la Pantera de 1990, y que protestaba contra un Decreto -convertido luego en Ley- de la antigua 
ministra de Educación del gobierno de Berlusconi, Maria Stella Gelmini, que tenía por objeto recortar sistemáticamente la subvención a las universidades públicas, en favor de las privadas y religiosas.

Al igual que en los ejemplos anteriores, numerosos periodistas, comentaristas políticos e intelectuales subrayaron la relevancia que redes sociales como Facebook habian jugado en la organización de eventos y en la coordinación de acciones entre los estudiantes, hasta el punto de calificar a la Ola como la primera "movilización 2.0" en Italia. Sin embargo, estudios etnográficos como el de Barassi y Treré (2012) han puesto en evidencia que el empleo que los estudiantes hicieron de las redes sociales y los social media fue, casi en la mayoria, unidireccional. Similar al caso del EZLN, los activistas hicieron un uso más bien "tradicional" y no tan innovador de estas redes -que se califica en el trabajo como Web 1.0-, puesto que se limitó a la mera divulgación de informaciones y no tanto al fomento del debate y la interacción en línea. Otros estudios han destacado que el empleo tecnológico más significativo fue el de las "viejas" listas de correo y distribución, que llevaban años integradas en las prácticas del activismo italiano, y en la trascendencia, a veces minusvalorada, que tomaron las reuniones y las asambleas locales, así como otros medios más tradicionales como folletos, radios estudiantiles y medios comunitarios (Treré, 2012).

El contexto italiano también proporciona otro caso emblemático y reciente de tecno-mitificación por parte de colectivos de carácter social y político. Nos referimos al Movimiento 5 Estrellas (Movimiento Cinque Stelle-M5S), liderado por el cómico y showman Beppe Grillo. Como ningún otro partido o movimiento ciudadano anterior, el M5S ha sabido aprovechar las posibilidades de interconexión y participación proporcionadas por Internet, y en particular por las plataformas de la Web 2.0. Y en buena medida estas resultaron cruciales para la visibilidad del movimiento de cara al éxito en las Elecciones Generales de 0ctubre de 2013, en la que el 5 Estrellas resultó ser el partido más votado (25,5\% de los sufragios), por encima del Partido Democrático $(25,4 \%)$ y del Pueblo de la Libertad $(21,5 \%)$.

A grandes rasgos, se puede afirmar que la estrategia online de Grillo funciona a diferentes niveles: en el centro se sitúa el blog beppegrillo.it, creado en 2005, que representa el verdadero corazón del movimiento y uno de los blogs más visitados e influyentes del mundo. Sus seguidores construyen a su alrededor tanto el programa político como su idea de democracia, fundados en una relación directa entre la res publica y los ciudadanos (Bordignon y Ceccarini, 2013). Pero la ecología online de Grillo es mucho más compleja e incluye los Meetup, plataformas de gestión y organización de grupos locales usadas para la creación de eventos y encuentros (el Movimiento 5 Estrellas cuenta actualmente con más de 600 Meetup en 14 paises), así como una masiva presencia en los social media, en particular YouTube, Facebook y Twitter.

Si bien no es objeto de este trabajo explorar a fondo la complejidad e innovación que subyace en sus estrategias comunicativas, tanto a nivel europeo como mundial, en el movimiento se evidencia de nuevo la construcción de discursos tecno-utópicos alrededor 
del potencial de Internet para la democratización. En este caso habría que subrayar las cada vez más constantes contradicciones entre los discursos ciber-optimistas de Grillo acerca del papel revolucionario de la red y la realidad del funcionamiento de un movimiento que se dice a sí mismo horizontal y ciudadano, pero en el que conviven también elementos de gestión vertical, jerárquica y empresarial de carácter más tradicional, bajo el liderazgo del cómico y de acuerdo a una estrategia online fuertemente centralizada a cargo del gurú tecnológico Roberto Casaleggio.

Por otra parte, en los discursos de Grillo a través de su blog o en sus múltiples producciones multimedia - DVDs, libros colectivos y monografias, material online en varias plataformas- es habitual la referencia a una serie de temáticas que constituirian la esencia del movimiento: la participación horizontal y transparente, la total ausencia de liderazgo y la democracia participativa basada en la fórmula del "uno vale uno", o la idea de que cada ciudadano cuenta como un voto o participación en total en igualdad y sin ningún tipo de discriminación. Pero todos estos mecanismos participativos son implementados de manera casi "mágica" a partir del uso intensivo de las plataformas digitales, en contraste con los medios tradicionales de comunicación -y en particular la prensa-, que son acusados por Grillo y los grillini de ser vestigios al servicio de unos poderes facticos que serán en breve remplazados por la información de las multitudes interconectadas.

Ya en el ámbito académico, algunos estudios acerca del uso de los medios digitales por el M5S han subrayado las virtudes de su discurso tecnológico innovador en un escenario político profundamente estático y conservador (Navarria, 2008; Turner, 2012). Sin embargo, en tiempos más recientes, en especial desde el ámbito periodístico (Mello, 2013; Santoro, 2012) y académico (Corbetta y Gualmini, 2013), la maquinaria político-tecnológica grillina ha empezado a ser cuestionada y analizada en algunas de sus evidentes contradicciones. Si los discursos tecno-optimistas de Grillo y Casaleggio exaltan la democracia del "uno vale uno" y si el movimiento no tiene líderes, resulta difícil explicar la gestión propietaria del símbolo del Movimiento 5 Estrellas que, de acuerdo con el non estatuto del movimiento, "resulta registrado a nombre de Beppe Grillo, el único propietario de los derechos de uso de este logo"7. El cómico tiene el poder absoluto de otorgar o rechazar el uso político y electoral del símbolo a cualquier grupo local, y posee entonces la facultad de expulsar militantes y miembros elegidos del movimiento según sus apetencias. De hecho, las expulsiones por parte de Grillo de activistas del 5 Estrellas como Giovanni Favia y Federica Salsi ${ }^{8}$ han llevado a varios militantes a cuestionar la gestión desde arriba del movimiento y a dudar de sus mecanismos democráticos internos.

En suma, las estrategias de este innovador movimiento se evidencian cada vez menos claras y transparentes, pese a sus reclamos constantes en este sentido. Incluso en los últimos años los conflictos entre la base y la cúspide han aumentado hasta poner de relieve que lo que en sus primeros momentos fue calificado de movimiento espontáneo

7 http://www.beppegrillo.it/iniziative/movimentocinquestelle/Programma-Movimento-5-Stelle.pdf

8 http://www.ilpost.it/2012/12/12/beppe-grillo-ha-espulso-salsi-e-favia/ 
y horizontal podria devenir con el tiempo en un astuto entramado político maquillado de política 2.0, pero dirigido en conjunto por Casaleggio y su empresa de marketing digital, Casaleggio y Asociados, y el "fabulador" Beppe Grillo, que aprovecha su inmensa capacidad oratoria tanto en el mundo online como en las plazas.

\section{Reflexiones finales y RUtas futuras}

Abrimos este análisis con una descripción sumaria de la tendencia a la mistificación que suele dominar en los primeros acercamientos a cualquier tecnología de la comunicación, en especial desde que la modernidad sustituyó la sublimación en torno a lo natural por discursos trascendentes acerca de los hallazgos fruto de la razón humana. A partir de ahí, se planteó un recorrido por un conjunto de nociones que ayudan a desentrañar la morfología del tecno-determinismo, en tanto que portador de valores y aspiraciones humanas, así como de falsas promesas acerca de la historia, la política o el tiempo. Seguidamente, nos acercamos al ciclo de creación y reproducción de los tecno-imaginarios, hasta situar a los movimientos sociales en un punto intermedio entre la reproducción del discurso institucional, periodístico o académico, y la superación del mismo mediante la apropiación tecnológica a efectos de reflexión y acción política.

Tras el recuento teórico, se propusieron cuatro estudios de caso situados en diferentes latitudes geográficas -EZLN en México, las "multitudes" filipinas" y la Ola Anómala y el Movimiento 5 Estrellas en Italia-, a efectos de ilustrar, por un lado, la tecno-euforia que acompaña a los primeros usos tecnológicos y, por otro, la deconstrucción a la que conduce su apropiación ordinaria. En este sentido, tanto la historia de la comunicación como su economía política se evidenciaron como vitales herramientas para una comprensión matizada de la relación entre movimientos y TIC, en tanto que perspectivas que invitan a insertar lo tecnológico en un marco de continuidades históricas, y a resituarlo críticamente en el contexto de procesos políticos, económicos o socioculturales de más largo alcance.

Todas estas reflexiones se propusieron a modo de antídoto contra la amnesia histórica que suele prevalecer en la reflexión sobre el activismo tecnológico, así como una ruta para pensar de modo diacrónico la relación entre movimientos y TIC tanto en el corto como en el largo plazo. En cuanto al primero, se reflejaron análisis que "absolutizan" el papel de los medios online en la irrupción de estallidos contemporáneos, y que no tienen en cuenta la dimensión procesual de los movimientos sociales ni el componente evolutivo de las propias plataformas tecnológicas, limitándose a la producción de "instantáneas" efímeras sobre la relación entre movimientos y medios (Monterde y Postill, 2013). En cuanto al largo plazo, otros estudios han tendido a subestimar los paralelismos del presente con respecto al pasado, en una clara tendencia a magnificar lo "nuevo" tecnológico de las insurrecciones, como si se tratase de tecno-movimientos auto-generados o espontáneos al amparo de unas TIC todopoderosas. 
Tomar en cuenta la dimensión diacrónica significa entonces superar la fascinación por el último hito o moda tecnológica, así como reconocer el uso ordinario o "banal" de las TIC y las continuidades históricas con respecto a contextos pretéritos. Se trataría pues de abandonar cierta "retórica de la sustitución", en la expresión de Gitelman (2006), en la que cada "nuevo" medio reemplaza en su totalidad a las antiguas técnicas, y de avanzar, en su lugar, hacia un marco en el que se interpreten las TIC en tanto que las "mediaciones" entre las apropiaciones populares y los usos hegemónicos (Martín Barbero, 1987; Gitelman, 2006), o desde el marco de las "remediaciones" (Bolter y Grusin, 2000), comprender que el contenido de un medio siempre reside en otro medio. De hecho, los estudios de caso abordados muestran las hibridaciones frecuentes entre las "viejas" y las "nuevas" tecnologías, así como la compleja interacción que prevalece entre las formas de comunicación online y offline en el seno de los movimientos.

Para concluir estas reflexiones, se considera necesario seguir profundizando en los perceptivos acercamientos a los movimientos sociales desde la perspectiva de las media practices o de prácticas relacionadas con los medios, en la línea de las reflexiones de Couldry (2004), de Martín Barbero (1987), otros investigadores (para una reseña sobre la relación entre prácticas y medios: Bräuchler y Postill, 2010), y de la que participan autores que critican la fascinación por la última moda tecnológica en el ámbito de los movimientos sociales (Barassi, 2009; Barassi y Treré, 2012; Barranquero, 2012; Cammaerts, Mattoni y McCurdy, 2013; Farinosi y Treré, 2010; Mattoni, 2012, 2013; McCurdy, 2011; Padovani, 2013; Treré 2011, 2012). De hecho, el enfoque de las media practices no privilegia ningún formato o tecnología en particular y arroja una mirada holística acerca de la mediación tecnológica, desde su inserción en un marco socio-histórico de largo alcance.

Finalmente se evidencia la importancia de investigar en torno a un fenómeno ciertamente desatendido en la reflexión sobre estos parámetros, y al que podriamos denominar la co-construcción de discurso tecnológico entre academia y movimientos sociales, y que abarcaría, desde desarrollos tecno-optimistas a miradas más complejas. Buen ejemplo de esto que afirmamos son movimientos como el 15M en España y el \#Yosoy132 en México, en los que se manifiesta una prolífica intersección entre activistas, estudiantes, profesores, hackers o profesionales de la información en el diseño de pensamiento sobre las tecnologías. En esta línea, destacamos el trabajo colectivo sobre el 15M coordinado por Javier Toret (2013) en el que, evitando recurrir a teorías y categorías ya fijadas, y alejándose de visiones simplistas basadas exclusivamente en la anécdota, se apoya en un análisis procesual y transdisciplinar de datos, redes, lenguajes, emociones y narraciones propias del movimiento. Los investigadores y activistas de este estudio desarrollan conceptos (tecnopolítica, multitudes conectadas, acontecimiento aumentado, contagio tecnológicamente estructurado y sistema red) y combinan herramientas de análisis de diferentes disciplinas (amplios datasets desde plataformas digitales, entrevistas cualitativas a activistas, análisis de emociones y de fractalidad, etc.) para abarcar el fenómeno $15 \mathrm{M}$ en toda su complejidad de sistema red mutante, híbrido (entre lo físico y lo virtual) 
y cyborg (que enlaza humanos y máquinas). Otro ejemplo de fértil polinización entre el campo académico y activista es representado por la publicación del libro colectivo The Militant Research Handbook (El manual de la investigación militante) (Bookchin et al. 2013), que recoge varios casos de estudios sobre movimientos sociales a lo largo del mundo (Argentina, España, India, Estados Unidos, Egipto), desde una perspectiva de encuentro entre activismo y academia que sirve para generar nuevas formas de actuar y de pensar las nuevas dinámicas contemporáneas de la acción colectiva.

La audacia y la experimentación metodológica, la búsqueda de enfoques innovadores, holísticos y poliédricos centrados en la exploración de las prácticas comunicativas de los actores, unidos a la prolífica intersección entre academia y activismo anticipan entonces sugerentes aproximaciones a la mediación tecnológica y señalan prometedoras rutas futuras por las que transitar a fin de cuestionar la tecno-fascinación y avanzar hacia ópticas más rigurosas y acreditadas.

\section{Referencias}

Adorno, Theodor y Horkheimer, Max (1994). Dialéctica de la ilustración. Fragmentos filosóficos. Madrid: Trotta. [Del original 1944].

Allen, Mathew (2008). "Web 2.0. An argument against convergence". First Monday, 13(3). Almirón, Nuria y Jarque, Josep Manuel (2008). El mito digital. Discursos hegemónicos sobre Internet y periodismo. Barcelona: Anthropos.

Aparici, Roberto (2000). "Trece mitos sobre las nuevas tecnologías de la información y de la comunicación". Tabanque. Revista Pedagógica, 14, 19-26.

Atton, Chris (2002). Alternative media. London: Sage.

Barassi, Veronica (2009). "Mediating political action: Internet related beliefs and frustrations amongst international solidarity campaigns in Britain". E. Ardèvol \& A. Roig (Coords.). Dossier Digitum, 11 "Researching media through practices: An ethnographic approach. Barcelona: Universitat Oberta de Catalunya. 20-25.

Barassi, Veronica y Treré, Emiliano (2012). “Does Web 3.0 come after Web 2.0? Deconstructing theoretical assumptions through practice". New Media \& Society, 14(8). 1269-1285.

Barranquero, Alejandro (2012). “Redes digitales y movilización colectiva. Del 15-M a nuevas prácticas de empoderamiento y desarrollo local". M. Martínez \&t F. Sierra (Coords.). Comunicación y desarrollo. Prácticas comunicativas y empoderamiento local. Madrid: Gedisa. 377-400.

Barthes, Roland (2010). Mitologías. México: Siglo XXI. [Del original 1957]

Bob, Clifford (2005). The marketing of rebellion. Insurgents, media, and international activism. Cambridge, UK: Cambridge University Press. 
Bolter, Jay David y Grusin, Richard A. (2000). Remediation. Understanding new media. Cambridge, MA: MIT.

Bookchin, Natalie; Brown, Pamela; Ebrahimian, Suzahn; colectivo Enmedio; Juhasz, Alexandra; Martin, Leónidas; MTL; Mirzoeff, Nicholas; Ross, Andrew; Saab, Joan A.; Sitrin, Marina (2013). Militant Research Hand-Book, New York University, disponible en: http:/l www.visualculturenow.org/wp-content/uploads/2013/09/MRH Web SinglePage.pdf

Bordignon F y Ceccarini L. (2013) Five Stars and a Cricket. Beppe Grillo shakes Italian politics. South European Society and Politics (versión ahead-of-print): 1-23.

Bräuchler, Birgit y Postill, John (eds.) (2010) Theorising Media and Practice. Oxford / New York: Berghahn.

Bustamante, Enrique (2009). "De las industrias culturales al entretenimiento. La creatividad, la innovación... Viejos y nuevos señuelos para la investigación de la cultura". Diálogos de la Comunicación, 78. 1-25.

Cabrera, Daniel H. (2004). "La matriz imaginaria de las nuevas tecnologías". Comunicación y Sociedad, 17(1). 9-45.

Cabrera, Daniel H. (2006). Lo tecnológico y lo imaginario. Las nuevas tecnologías como creencias y esperanzas colectivas. Buenos Aires: Biblos.

Cammaerts, Bart, Mattoni, Alice y McCurdy, Patrick (eds.) (2013). Mediation and protest movements. Bristol: Intellect.

Candón Mena, José (2013). Toma la calle, toma las redes: El movimiento 15M en Internet. Sevilla: Atrapasueños.

Carey, James W. (2002). Communication as culture. New York / London: Routledge.

Carr, Nicholas (2011). Superficiales. ¿Qué está haciendo Internet con nuestras mentes? Madrid: Taurus.

Castells, M. (1998). La era de la información. El poder de la identidad. Vol. 2. Madrid: Alianza.

Castells, Manuel (2009). Comunicación y poder. Madrid: Alianza.

Castells, Manuel (2013). Redes de indignación y esperanza. Madrid: Alianza.

Cleaver, Harry M. (1994). "The Chiapas uprising and the future of class struggle in the new world order". RIFF-RAFF. Consultado el 14/07/13 en:

gopher://mundo.eco.utexas.edu:70/11/fac/hmcleave/cleaver\%20Papers

Corbetta, Pierluigi y Gualmini, Elisabetta (Eds.) (2013). Il partito di Grillo. Bologna: II Mulino. Couldry, Nick (2004). "Theorizing media as practice". Social Semiotics, 14(2). 115-132.

Darnton, Robert (2011). "Five myths about the information age". Chronicle of Higher Education, 17 de abril.

Dyer-Witheford, Nick (1999). Cyber-Marx: Cycles and circuits of struggle in high technology capitalism. Illinois: University of Illinois.

Ellul, Jacques (1960). El siglo XX y la técnica. Análasis de las conquistas y peligros de la técnica de nuestro tiempo. Barcelona: Labor. [Del original 1954].

Farinosi, Manuela y Treré, Emiliano (2010). "Inside the "People of the Wheelbarrows": par- 
ticipation between online and offline dimension in the post-quake social movement. The Journal of Community Informatics, 6 (3).

Flichy, Patrice (2003). Lo imaginario de Internet. Madrid: Tecnos. [Del original 2000].

Fuchs, Christian (2008). Internet and society: Social theory in the information age. New York: Routledge.

Fuchs, Christian (2012). "Some reflections on Manuel Castells' book 'Networks of outrage and hope'. Social movements in the Internet Age". tripleC, 10(2). 775-797. Consultado el 14/07/13 en: http://www.triple-c.at/index.php/tripleC/article/view/459

Fuchs, Christian (2013). "Social media and capitalism". T. Olsson (Ed.). PRODUCING THE INTERNET. CRITICAL PERSPECTIVES OF SOCIAL MEDIA. Göteborg: Nordicom. 25-44.

Gerbaudo, Paolo (2012). Tweets and the streets. Social media and contemporary activism. London: Pluto Press.

Gitelman, Lisa (2006) Always already new: Media, history and the data of culture. Cambridge, MA: MIT.

Grönlund, Åke (2009). "ICT is not participation is not democracy - eParticipation development models revisited". A. Macintosh, \& E. Tambouris (Eds.). Electronic Participation. First International Conference, ePart Proceedings. Berlin / Heildelberg: Springer. 12-23.

Habermas, Jürgen (1997). Ciencia y técnica como ideología. Madrid: Tecnos. [Del original 1968]. Heidegger, Martin (1984). Ciencia y técnica. Santiago de Chile: Eidtoarial universitaria. [Del original 1954].

Heidegger, Martin (1989). Serenidad. Barcelona: Del Serbal. [Del original 1959].

Hellman, Judith Adler (2000). "Real and virtual Chiapas: Magic realism and the left". Socialist Register, vol. 36. 161-186.

Howard, Philip N. y Parks, Malcolm R. (2012). "Social media and political change: capacity, constraint, and consequence". Journal of Communication, 62. 259-362.

Illich, Ivan (1985). La convivencialidad. México: Morelos. [Del original 1973].

Jonás, Hans (1995). El principio de responsabilidad. Ensayo de una ética para la civilización tecnológica. Barcelona, Herder. [Del original 1979].

Kotamraju, Nalini P. (2005). "Review of Smart Mobs: The Next Social Revolution by Howard Rheingold". Social Forces, 83(4), 1765-1767.

Lasén, Amparo y Martínez de Albeniz, Iñaki (2011). "'An original protest, at least'. Mediality and participation". H. Greif, L. Hjorth, A. Lasén y C. Lobet-Maris (Eds.). The cultures of participation. Media practices, cultures and literacy. Berlin: Peter Lang. 141-158.

Lerner, Daniel (1958). The passing of the traditional society. Modernizing the Middle East. Glencoe, II: The Free Press.

Lévy, Pierre (2004). Inteligencia colectiva. Por una antropología del ciberespacio. Washington DC.: Bireme/OPS/OPM. [Del original 1994].

Mari Sáez, Víctor (2011). Comunicar para transformar, transformar para comunicar. Tecnologías de la información desde una perspectiva de cambio social. Madrid: Popular. 
Martín-Barbero, Jesús (1987). De los medios a las mediaciones. Comunicación, cultura y hegemonía. Barcelona: Gili.

Mattelart, Armand (1995). La invención de la comunicación. México: Siglo XXI.

Mattelart, Armand (1999): Historia de la utopía planetaria: de la ciudad profética a la sociedad global. Barcelona: Paidós.

Mattelart, Armand (2002). Historia de la sociedad de la información. Barcelona: Paidós.

Mattoni, Alice. (2012). Media practices and protest politics: How precarious workers mobilise. Farnham: Ashgate.

Mattoni, Alice. (2013). "Repertoires of communication in social movement processes". B. Cammaerts, A. Mattoni y P. McCurdy (Eds), Mediation and protest movements. Bristol, UK: Intellect. 39-87.

McChesney, Robert W. (2012). Digital disconnect: How capitalism is turning the Internet against democracy. New York, NY: New Press.

Maxwell, Richard y Miller, Toby (2012). Greening the media. New York: Oxford University Press. McCurdy, Patrick (2011). "Theorizing activists' 'lay theories of media': A case study of the Dissent! network at the 2005 G8 Summit". International Journal of Communication, 5. 619-638.

Mello, Federico (2013). Il lato oscuro delle stelle. La dittatura digitale di Grillo e Casaleggio. Testimonianze, documenti e retroscena inediti. Reggio Emilia: Imprimatur.

Melucci, Alberto (2001). Vivencia y convivencia: teoría social para una era de la información. Madrid: Trotta.

Mitcham, Carl (1989). ¿Qué es la filosofía de la tecnología? Barcelona; Anthropos.

Monterde, Arnau y Postill, John (forthcoming 2013). "Mobile ensembles: The uses of mobile phones for social protest by Spain's indignados". G. Goggin \& L. Hjorth (eds.). The Routledge Companion to Mobile Media. London: Routledge.

Morozov, Eugeny (2012). El desengaño de Internet. Los mitos de la libertad en la red. Barcelona: Destino.

Morozov, Eugeny. (2013). To save everything, click here: The folly of technological solutionism. New York, NY: Public Affairs.

Mosco, Vincent (2011). Sublimidad digital. Ciberespacio, mito y poder. México: Universidad Veracruzana. [Del original 1994].

Mumford, Lewis (1971). Técnica y civilización. Madrid: Alianza. [Del original 1934].

Mumford, Lewis (2010). El mito de la máquina. Técnica y evolución humana. Logroño: Pepitas de Calabaza. [Del original 1967].

Mumford, Lewis (2011). El pentágono del poder. El mito de la máquina (vol. 2). Logroño: Pepitas de Calabaza. [Del original 1970].

Navarria, Giovanni (2008). "Political anomalies and web-based civil antibodies in Silvio Berlusconi's Bel Paese". Recerca: revista de pensament y anàlisi, 8, 173- 192.

Nye, David E. (1996). American technological sublime. Cambridge, MA: MIT.

O'Reilly, Tim (2005). "What is Web 2.0: Design patterns and business models for the next 
generation of software". O'Reilly Group. Consultado el 14/07/13 en: www.oreilly.com/pub/a/oreilly/tim/news/2005/09/30/what-is-web-20.html

Ortega y Gasset, José (1997). Meditación de la técnica. Madrid: Santillana. [1ª ed. 1933]. Padovani, Cinzia (2013). "Activists' communication in a post-disaster zone: cross-media strategies for protest mobilization in L'Aquila, Italy". B. Cammaerts, A. Mattoni \& P. McCurdy (eds.). Mediation and protest movements. Bristol, UK: Intellect. 179-205.

Pinto, María Cristina (2013). La construcción de la referencia en torno al concepto de brecha digital en España. Universidad Complutense de Madrid. Tesis doctoral no publicada. Pitman, Thea (2007). "Latin American cyberprotest: Before and after the

Zapatistas". C. Taylor y T. Pitman (eds.). Latin American cyberculture and cyberliterature, Liverpool: Liverpool University Press. 86-111.

Postill, John (2012). "Media and social changing since 1979: Towards a diachronic ethnography of media and actual social changes". EASA 2012 biennial conference, Nanterre, Paris. Consultado el 13/07/2013 en: http://johnpostill.com/papers

Postman, Neil (1994). El culto a la información: tratado sobre alta tecnología, inteligencia artificial y el verdadero arte de pensar. Barcelona: Círculo de Lectores. [Del original 1992].

Rafael, Vicente Leuterio (2003). "The cell phone and the crowd: Messianic politics in the contemporary Philippines". Public Culture, 15(3), 399-425.

Rheingold, Howard (2004). Multitudes inteligentes: la próxima revolución social, BarceIona: Gedisa. [Del original 2003]

Rhodes, Neil y Sawday, Jonathan (2000). The Renaissance computer. Knowledge technology in the first age of print. London: Routledge.

Ronfeldt, David et al. (1998). The Zapatista social netwar in Mexico. Santa Monica, CA: RAND.

Roszak, Theodore (2005). El culto a la información. Barcelona: Gedisa. [Del original 1994] Russell, Adrienne (2005). "Myth and the Zapatista movement: exploring a network identity". New Media \& Society, 7(4). 559-577.

Sádaba, Igor. (2012). "Acción colectiva y movimientos sociales en las redes digitales. Aspectos históricos y metodológicos". Arbor, 188 (76). 781-794.

Santoro, Giuliano (2012). Un grillo qualunque. II movimiento 5 stelle e il populismo digitale nella crisi dei partiti italiani. Roma: Castelvecchi.

Saperas, Enric (1992). La sociología de la comunicación de masas en los EE.UU. Barcelona: Ariel. Schramm, Wilbur (1964). Mass media and national development. The role of information in the developing countries. Stanford: Stanford University Press-SUP.

Scholz, Trebor (2008). "Market ideology and the myths of Web 2.0". First Monday, 13(3).

Schwarzenegger, Christian (2012). "Exploring digital yesterdays - Reflections on new media and the future of communication history". Historical Social Research, 37. 118-133.

Shirky, C. (2011). The political power of social media: Technology, the public sphere, and political change. Foreign Affairs, 90(1), 28-41. 
Sierra, Francisco (2006) Políticas de comunicación y de educación. Crítica y desarrollo de la sociedad del conocimiento. Barcelona: Gedisa.

Toret, Javier; Aguilera, Miguel; Aragón, Pablo; Calleja, Antonio; Lumbreras, Alberto y Marín, Óscar (2013). Tecnopolítica: la potencia de las multitudes conectadas. El sistema red 15M, un nuevo paradigna de la política distribuida. IN3 Working Paper Series.

Thierer, Adam (2010). "The case of Internet Optimism, Part 1: Saving the Net form its detractors". B. Szoka y A. Markus (Eds.). The next digital decade. Essays on the future of the Internet. Washington DC: Techfreedom. 57-88.

Tilly, Charles (2004). Social Movements, 1768-2004. London: Paradigm.

Tilly, Charles (2005). "Los movimientos sociales entran en el siglo veintiuno". Política y Sociedad, 42(2). 11-35.

Treré, Emiliano. (2011). "Nuevos movimientos sociales, activismo digital y nuevas tecnologías de la comunicación". M. Herrera Aguilar (Ed.). Cuartas Jornadas: la comunicación como objeto de estudio. Teoría y prácticas en ciencias sociales. Memorias. Querétaro: Universidad Autónoma de Querétaro. 1-9.

Treré, Emiliano. (2012). "Social movements as information ecologies: Exploring the coevolution of multiple Internet technologies for activism". International Journal of Communication, 6. 2359-2377.

Turkle, Sherry (2011). Alone together. Why we expect more from technology and less from each other. New York, NY: Basic Books.

Turner, Eric (2013). The Grillini in Italy: New Horizons for Internet-based Mobilization and Participation, Social Movement Studies: Journal of Social, Cultural and Political Protest, 12:2, 214-220.

Wellman, Barry (2004). "The three ages of Internet studies: Ten, five and zero years ago". New Media and Society, 6. 123-129.

Wellman, Barry (2011). "Studying the Internet through the ages". M. Consalvo y C. Ess (Eds.). The handbook of Internet studies. Chichester, UK: Blackwell. 43-57.

Winner, Langdom (2008). La ballena y el reactor. Barcelona: Gedisa. [1ª ed. 1986]. 